\title{
The effect of Emotional intelligence on Turnover intention through the mediation of work-life conflict: The case of commercial bankers in Vietnam
}

\author{
Bui Nhat Vuong \\ Tushar Hasanuzzaman \\ Tran Nhu Quan \\ National Institute of Development Administration, Thailand
}

\begin{abstract}
The aim of this research is to examine the effect of emotional intelligence on turnover intention, noting the mediating roles of work-family conflict and job burnout. Survey data collected from 198 employees at commercial banks in Vietnam was analyzed to provide evidence. Results from the partial least squares structural equation modeling (PLSSEM) using SmartPLS 3.0 program indicated that there was a negative impact of emotional intelligence on employees' turnover intention; this was mediated partially through work-family conflict and job burnout. The main findings of this research provided some empirical implications for commercial banks. It implied that organizations in the service industry should give a try to improve their people's work-family balance, reduce job burnout and take advantages of these emotional balance to create beneficial outcomes.
\end{abstract}

Keywords: emotional intelligence, work-family conflict, job burnout, employees' turnover intention, Vietnamese commercial banks 